2001

\title{
Dose-Banding of cytotoxic drugs: A new concept in cancer chemotherapy
}

Sewell, GJ

http://hdl.handle.net/10026.1/3738

10.1093/ajhp/58.18.1760

American Journal Health-Systems Pharmacy

Oxford University Press (OUP)

All content in PEARL is protected by copyright law. Author manuscripts are made available in accordance with publisher policies. Please cite only the published version using the details provided on the item record or document. In the absence of an open licence (e.g. Creative Commons), permissions for further reuse of content should be sought from the publisher or author. 


\section{Dose-banding of cytotoxic drugs: A new concept in cancer chemotherapy}

\author{
RTCHARD ] PLUMRDOE AND GRAHAM I. SEWEU
}

\author{
Am J Health-Syst Pharm. 2001; 58:1760-4
}

D oses of cytotoxic drugs have traditionally been calculated on the basis of body surface area (BSA), the only exception being carboplatin, for which the dose is calculated on the basis of renal function and targeted area under the plasma concentration-time curve. The use of BSA for dosage calculation arises from Phase I drug development, when animal doses are recalculated for humans on the basis of BSA. ${ }^{1}$ This practice has continued into the later drug development phases and, after marketing approval, into clinical practice. ${ }^{1.2}$ As a result, each dose of cytotoxic drug is individualized for each patient in accordance with current hematology test results and is usually prepared immediately before administration. The calculated dose may be rounded to account for the degree of accuracy possible with ampuls and vials. Individual preparation results in increased demand on pharmacy intravenous admixture and cytotoxic drug services, often causing delays for patients awaiting treatment; it can also disrupt scheduling, limit the number of patients hospital clinics can treat, and cause inefficiencies in the use of nursing resources. In response to the reactive nature of cytotoxic drug preparation and its consequences, a few hospitals in the United Kingdom have introduced "dose-banding" for a limited number of cytotoxic drugs.
Little has been published about dose-banding. We gathered information between June and August 2000 on the feasibility of dose-banding cytotoxic drugs in daily clinical practice. This article reports the results of that effort, provides a formal definition of dose-banding, discusses the concept and relative merits of dose-banding cytotoxic drugs, describes which cytotoxic drugs are most amenable to dose-banding, and discusses issues relevant to implementing the practice.

\section{information gathering}

A comprehensive literature search was conducted to identify publications relating to dose-banding in MEDLINE (1966 to June 2000), Embase (1980 to present), and PharmLine and International Pharmaceutical Abstracts (1980 to present). Search terms used were "dose-banding," "dosage banding," "dose and banding," and "antineoplastics and dose calculation." A man-

RICHARD J. PLUMRIDGE, M.B.A., is Director of Pharmacy, Fremantle Hospital and Health Service, Fremantle, Western Australia, Australia; when this article was written he was International Research Fellow, Department of Pharmacy and Pharmacology, University of Bath (UB), Bath BA2 7AY, United Kingdom. Graham J. Sewell, Ph.D., is Professor of Clinical Pharmacy and Pharmacy Practice, Department of Pharmacy and Pharmacology, UB.

Address correspondence to Mr. Plumridge at Fremantle Hospital and Health Service P.O. Box 480, Fremantis, W.A. 6959, Australia (richard.plumridge@ $@$ health.wa.gov.au). ual and Internet-based search of relevant journals not indexed in the above databases (e.g., the Journal of Oncology Pharmacy Practice and the Pharmaceutical Journal) was undertaken.

Structured interviews were conducted with 17 pharmacists in 13 hospitals in England, Wales, and the Republic of Ireland that provide major cancer chemotherapy (including 7 hospitals using dose-banding for selected cytotoxic drugs; in 5 of these, oncology nurses were also interviewed) to collect information based on the objectives previously described. The hospitals prepared 20,000-65,000 individual cytotoxic injections annually. A focus-group meeting attended by pharmacists and a senior nurse was then held in August 2000 . The information resulting from the hospital survey was presented to the group, and a consensus on key issues was reached.

The database review did not identify any citations related to dosebanding; however, manual searching identified two articles. ${ }^{3,4}$ The earliest identified use of the term "dosebanding" occurred in 1996 in a brief (half-page) news article describing the system developed at the University Hospital Birmingham National

The contributions of the following are acknowledged: Nicola Allbut, Rebecca Anderson, Leslie Beattic, Carolyn Daniel, Libby Hardy, Meena Hunjun, Tony Johnson, Sarah Jones, Jeff Koundakjian, Jan Loving, Fiona MacLean, Tony McConkey, Oonagh McGrath. Dr. Richard Needle, Dr. John Pickup, Simon Rivers, Rosie Roberts, Tim Root, Kamal Sabra, June So, Dr. Nicola Stoner, Dr. Max Summerhayes, Richard Wastnage, and Nicola Wong.

Copyright (c) 2001. American Society of Health-System Pharmacists, Inc. All rights reserved. 1079-2082/01/0902-1760\$06.00. 
Health Science Trust. ${ }^{3}$ "Dose-banding" was used only in the headline, and the system was described as involving "the use of prefilled syringes containing a predetermined range of doses. For each patient, the correct dose is dispensed by the use of one or, if necessary, two of the prefilled syringes." Details on the system's development were published by Baker and Jones ${ }^{4}$ in 1998. These authors did not formally define dose-banding but stated only that "a 'dose-banding' system was developed, enabling the same dose to be used for a range of body surface areas."

\section{Definition of dose-banding}

Because no formal definition of dose-banding appeared to exist, the focus group drafted one:

Dose-banding is a system whereby, through agreement between prescribers and pharmacists, doses of intravenous cytotoxic drugs calculated on an individualized basis that are within defined ranges or bands are rounded up or down to predetermined standard doses. The maximum variation of the adjustment between the standard dose and the doses constituting each band is $5 \%$ or less. A range of prefilled syringes or infusions, manufactured by pharmacy staff or purchased from commercial sources, can then be used to administer the standard dose.

\section{Concept of dose-banding}

The description of a dose-banding service by Baker and Jones ${ }^{4}$ applied to the use of intravenous methotrexate and fluorouracil. The system was introduced to overcome long delays in supplying individually prepared cytotoxic injections to patients. BSAs, expressed in intervals of 0.05 $\mathrm{m}^{2}$, were placed into bands 0.05 to $0.15 \mathrm{~m}^{2}$ wide. For example, one fluorouracil band contained the BSAs of 1.70 and $1.75 \mathrm{~m}^{2}$, and the next band contained the BSAs of $1.80,1.85$, 1.90 , and $1.95 \mathrm{~m}^{2}$ (Table 1). Each increment of BSA was used to calculate the individualized doses within each band. For a fluorouracil dose of 600 $\mathrm{mg} / \mathrm{m}^{2}$, for example, the individualized doses for the band containing BSAs of 1.70 and $1.75 \mathrm{~m}^{2}$ were 1020 and $1050 \mathrm{mg}$, respectively. A single standard dose (1025 $\mathrm{mg}$ for the same example) was then administered for all individualized doses falling within that band by using prefilled syringes of various strengths of each cytotoxic drug. The variance of the standard dose for the bands was set at no greater than $5 \%$ of that originally calculated for individualized doses. Five strengths of each cytotoxic drug were prepared in prefilled syringes, allowing for either one syringe or a combination of two to be used for all doses administered. Baker and Jones ${ }^{4}$ reported that $95 \%$ of all outpatient therapy was able to be provided via the prefilled syringes, without any measurable decrease in patient care. Positive effects included an increase in the number of patients who could be treated per clinic and a decrease in patient waiting times.

Different methods can be used to construct the dose-bands. Baker and Jones ${ }^{4}$ devised bands of BSAs of various widths and used them to calculate doses within each band (Table 1). An alternative approach is to decide on an acceptable width of a band for a cytotoxic drug (e.g., $50 \mathrm{mg}$ ) and to administer a standard dose for all in- dividualized doses (calculated with BSA) that fall into that band. The standard dose is the midpoint of the band, resulting in a maximum variance in dose of half the band (thus, if the band is $50 \mathrm{mg}$, the maximum variance is $25 \mathrm{mg}$ ). This method does not create bands based on BSA but on predetermined band widths within dose ranges (Figure 1). As Table 2 shows, this method takes the dose calculated with BSA (e.g., $1.60 \mathrm{~m}^{2} \times$ fluorouracil $600 \mathrm{mg} / \mathrm{m}^{2}=$ fluorouracil $960 \mathrm{mg}$ ) and places it into the appropriate band from which the standard dose is then chosen (in this example, fluorouracil $950 \mathrm{mg}$ ). This method involves less initial work than that based on banding by BSA, as no BSA bands need to be established for each cytotoxic. It also permits prescribers to continue to calculate the individualized dose, as currently occurs in clinical practice. A standard dose is then selected from tables for each cytotoxic by the prescriber when writing the prescription and is checked by a pharmacist before the dose is prepared.

\section{Relative merits of dose-banding}

Reasons in favor. The pharmacists interviewed expressed strong, almost universal support for dose-banding, stating that it reduces the urgency for the pharmacy staff to prepare individualized doses. Increasing patient

Table 1.

Dose-Banding Scheme for Fluorouracil Based on Grouping by Body Surface Area (BSA) a

\begin{tabular}{|c|c|c|c|c|}
\hline $\operatorname{BSA}\left(\mathrm{m}^{2}\right)$ & $\begin{array}{l}\text { Calculated } \\
\text { Dose (mg) }\end{array}$ & $\begin{array}{l}\text { Standard } \\
\text { Dose (mg) }\end{array}$ & Syringes Used & $\begin{array}{l}\text { Variance, } \\
\text { mg }(\%)^{d}\end{array}$ \\
\hline Band 1 & & 1025 & $125 \mathrm{mg}+900 \mathrm{mg}$ & \\
\hline 1.70 & 1020 & & & $5(0.5)$ \\
\hline 1.75 & 1050 & & & $25(2,4)$ \\
\hline Band 2 & & 1125 & $125 \mathrm{mg}+1000 \mathrm{mg}$ & \\
\hline 1.80 & 1080 & & & $45(4.0)$ \\
\hline 1.85 & 1110 & & & $15(1.3)$ \\
\hline 1.90 & 1140 & & & $15(1.3)$ \\
\hline 1.95 & 1170 & & & $45(4.0)$ \\
\hline
\end{tabular}

adapted from reference 4. Two dose bands only are shown as examples.

bFor fiuorouracil $600 \mathrm{mg} / \mathrm{m}^{2}$

In this example, prefilled syringes contain fluorouracil 125,500, 750, 900, or $1000 \mathrm{mg}$.

absolute difference between the standard and calculated doses. Percentage is based on the difference from the standard dose. 
Figure 1. Schema of dose-banding with a predetermined band width of $50 \mathrm{mg}$. In this example, a cytotoxic drug given at $600 \mathrm{mg} / \mathrm{m}^{2}$ for a $1.60-\mathrm{m}^{2}$ person (a $960-\mathrm{mg}$ dose) would fall within the dose range from 926 to $975 \mathrm{mg}$ and result in a standard dose of $950 \mathrm{mg}$ being
administered.

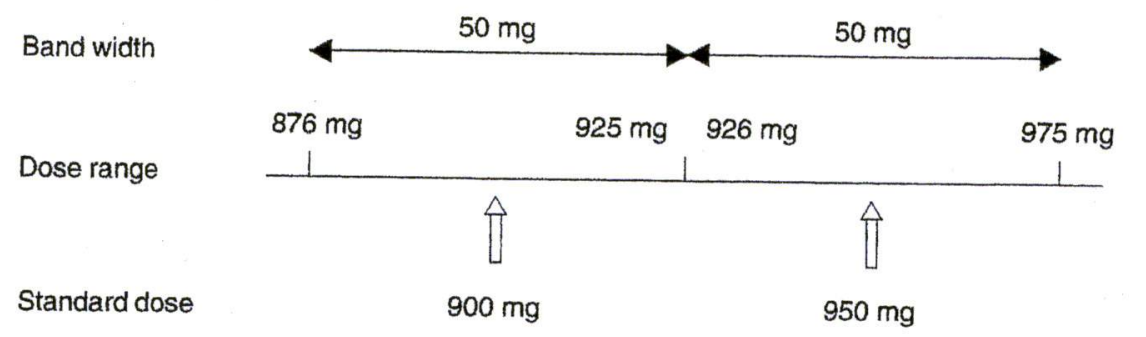

Maximum variance between standard dose and doses within dose range

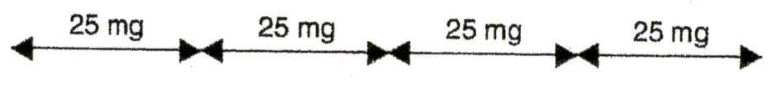

Table 2.

Dose-Banding Scheme for Fluorouracil Based on Grouping by Dose Range ${ }^{a}$

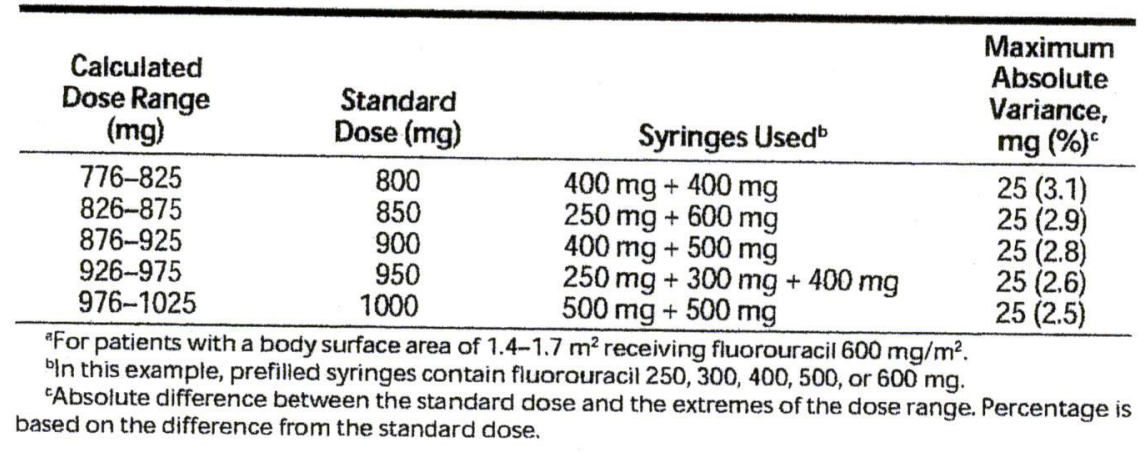

throughput and aseptic workload in many hospitals was creating considerable staff stress, as patients' doses were often not available when required. It was perceived that dose-banding would reduce complaints from nurses, oncologists, and patients about lengthy waiting times. All pharmacists surveyed believed that the variance from the standard dose within each band must be $5 \%$ or less. This figure appears to be based on professional training and traditional pharmacopoeial limits regarding dose variance.

The pharmacists also believed that dose-banding was, or would be, strongly supported by nurses because of reduced waiting times for prepared doses, improved service to patients, more efficient use of nursing time, and potential to treat more pa- tients during normal clinic hours. This was confirmed in discussions with oncology nurses.

Support from oncologists was rated as strong by approximately $70 \%$ of the pharmacists. Three factors accounted for this support: reduced patient waiting times, the limitation of dose variance to $5 \%$ or less, and the belief that, because dosing based on BSA is not totally accurate,,$^{1,2,5-7}$ dosebanding would not introduce additional variance (an increase or a decrease) that could affect toxicity and clinical outcomes.

Although over half of the pharmacist and nurse interviewees believed that there would be strong support from patients for dose-banding, this was difficult to gauge because no direct measurement, through surveying, was undertaken. The surrogate measures used - the opinions of oncology nurses and pharmacists based on feedback from patients or from pharmacists based on feedback from nurses-were positive. In hospitals that had implemented dose-banding, it was believed that patients had noticed reduced waiting times for their therapy (even though most would not have been aware of the specific reason).

Strong support from hospital management was evident when there were organizational reasons for management to be aware that dose-banding had, or could, improve the quality of patient services or reduce the cost of preparing antineoplastic doses.

Thus, the survey found the following chief factors in support of dose-banding (listed in order of importance):

- Reduction in complaints from nurses and oncologists regarding the time between the receipt of a prescription in the pharmacy and the availability of the cytotoxic drug.

- Reduced stress on pharmacy staff.

- The acceptability of a variance of $5 \%$ or less from the standard dose within each band.

- Reduced complaints from patients about service times.

- The capacity not to add significant dose variance to that resulting from BSA estimation.

Other reasons cited in favor of dose-banding included a reduction in drug waste by eliminating failure to use the complete contents of ampuls or vials when preparing individual doses, the ability to reuse prefilled syringes if administration is canceled, and lower preparation costs (batch manufacturing or purchasing from industry reduces unit production time and involves staff with a lower average pay rate). Batch preparation of cytotoxic drug infusions requires rigorous validation of chemical, physical, and microbiological stability. ${ }^{8}$ This 
approach enables sampling the finished batch for quality-control testing before release to patients. Batch preparation also facilitates sterility testing to determine whether pharmacopoeial standards are met, ${ }^{9}$ an approach precluded, in the case of small numbers of infusions prepared for individual patients, by sample size and probability considerations. ${ }^{10}$

Reasons against. Just under $40 \%$ of the interviewees believed that some oncologists may have reasons to oppose dose-banding. The major reasons against were as follows:

- The dose variance introduced by dose-banding, when combined with the estimation of BSA in calculating doses, may result in an unacceptable total variance from the intended dose.

- Some oncologists insist on the "clinical freedom" to have individually calculated doses prepared and administered. (This issue could be resolved through direct communication focusing on the relative preparation times and patient waiting times and on the realities that dose rounding to the nearest measurable dose occurs and that polypropylene syringes vary in volume.)

- Since prescribers do not usually participate in the drug-use process after writing a prescription, they are often unaware of some of the practical reasons supporting the introduction of dose-banding, especially the impact on patients, nurses, and pharmacists.

Other reasons for oppositionmost of which can be readily addressed-include the requirement to use more than one syringe to administer a dose. What is an acceptable maximum number of syringes required to administer a dose? The optimal maximum appears to be two or possibly three. Discussions with oncology nurses working in hospitals where dosebanding had been implemented did not indicate any practical problems in using two or three syringes. Syringe size determines nurses' ability to give an injection easily. As syringe size increases, the manual dexterity required in handling and the pressure needed to depress the plunger increase. Nurses interviewed had not experienced problems using syringes of up to $50 \mathrm{~mL}$ containing less than 50 $\mathrm{mL}$ of cytotoxic drug, although further investigation of this is needed.

Risk can be minimized by providing written procedures and educational programs for oncologists, oncology nurses, and pharmacists before dosebanding is implemented.

\section{Cytotoxic drugs amenable to dose-banding}

Fluorouracil, cyclophosphamide, methotrexate, doxorubicin, and epirubicin appear to be most amenable to dose-banding, along with the noncytotoxic agent leucovorin calcium. These drugs represent a considerable proportion of all cytotoxic doses administered, and each has stability data to permit batch manufacturing. Analysis of syringe-strength combinations results in the minimum number of syringes needed to administer standard doses over the dose ranges used in clinical practice (Table 3 ).

The decision to dose-band methotrexate, doxorubicin, epirubicin, and leucovorin calcium is dependent on the dose range. In hospitals where this range is relatively narrow (e.g., methotrexate 60 to $80 \mathrm{mg}$ [as the sodium salt]), a limited number of syringes can be used (e.g., 5-mg increments), thus obviating the need for dosebanding. When the dose range is wider (e.g., methotrexate 50 to $100 \mathrm{mg}$ ), dose-banding is preferred because fewer syringe strengths are required that, when combined, permit all standard doses to be administered.

\section{Issues in implementing dose- banding}

In introducing dose-banding, a well-designed educational program must be used that incorporates open communication. As pharmacists will usually have the greatest incentive to promote dose-banding, this communication will, initially, involve pharmacists (especially clinical oncology pharmacists and i.v. admixture production managers) drafting a proposal. This proposal should include the definition of dose-banding, an

Table 3.

\section{Dose-Banding and Syringe Scheme for Drugs Commonly Used in Oncology}

\begin{tabular}{|c|c|c|c|}
\hline $\begin{array}{l}\text { Drug and Dose } \\
\text { Range (mg) }\end{array}$ & $\begin{array}{l}\text { Width of } \\
\text { Dose Bands } \\
\text { (mg) }\end{array}$ & Standard Syringes (mg) & $\begin{array}{c}\text { No. } \\
\text { Syringes } \\
\text { Needed } \\
\text { for Standard } \\
\text { Dose }\end{array}$ \\
\hline $\begin{array}{l}\text { Fluorouracil } \\
500-1000 \\
1100-1500\end{array}$ & $\begin{array}{r}50 \\
100\end{array}$ & $250,300,400,500,600,1000$ & $1-3$ \\
\hline $\begin{array}{l}\text { Cyclophosphamide } \\
500-1000 \\
1100-1800\end{array}$ & $\begin{array}{r}50 \\
100\end{array}$ & $250,300,400,500,600,1000$ & $1-3$ \\
\hline $\begin{array}{l}\text { Methotrexate } \\
50-100\end{array}$ & 5 & $15,50,55,60,80$ & 1 or 2 \\
\hline $\begin{array}{l}\text { Doxorubicin hydrochloride } \\
50-120\end{array}$ & 5 & $10,15,20,40,50$ & $1-3$ \\
\hline $\begin{array}{l}\text { Epirubicin hydrochloride } \\
50-200\end{array}$ & 5 & $10,15,20,40,50,100$ & $1-4$ \\
\hline $\begin{array}{l}\text { Leucovorin calcium }^{b} \\
25-50\end{array}$ & 5 & $5,10,25,40$ & 1 or 2 \\
\hline
\end{tabular}

${ }^{a}$ Doses expressed in terms of the sodium salt.

boses expressed in terms of leucovorin. 
explanation of the concept and the relative merits, and details on amenable drugs and syringe strengths and can be used to facilitate personal communication with oncologists and nurses. Using established professional networks (e.g., having a pharmacist who is particularly well respected by oncologists and nurses give a presentation) should be considered. In addition, informal discussions with key decision-makers, both in oncology and nursing, will assist in education, as well as provide valuable feedback on possible barriers and the potential for acceptance. Negotiation with hospital management and committees may also be required.

Printed information should be provided for each cytotoxic as a guide to calculating standard doses. Patient education should emphasize that the use of multiple syringes does not mean that the patient's usual dose has been increased.

Risk management requires the continuation of dispensing prefilled syringes rather than supplying these to wards and clinics as stock items; this maintains essential checks at the prescribing, dispensing, and administration stages by an oncologist, a pharmacist, and a nurse, respectively. Each syringe must be labeled with the patient's name, the date of dispensing, and the number of syringes needed for the total dose. Written procedures are essential.

With respect to syringes that require refrigeration, the administration of cold i.v. solutions may cause vasoconstriction at the site of administration, usually resulting in a cold sensation. On rare occasions, though, thrombophlebitis may result. Thus, sufficient time should be allowed for the solution to reach room temperature. Allowing a standard time period to elapse for set vol- umes is preferable to using mechanical means. Microwave ovens have the potential to overheat or unevenly heat liquids, and heating coils may be unreliable and do not permit the temperature of the syringe contents to be appropriately monitored. Alternatively, a heating pad may be placed adjacent to the administration site in an effort to reverse any vasoconstriction.

Prefilled syringes could be prepared in a licensed hospital pharmacy facility or manufactured by the pharmaceutical industry. The latter is attractive in many countries (e.g., Australia and the United Kingdom) because of continuing difficulties in recruiting hospital pharmacy staff and increasing workloads, which are making it harder to meet service commitments. No national data are available to estimate the cost savings of dose-banding versus individualized preparation or whether dose-banding affects medication errors. However, the interviews revealed that the pharmaceutical industry is viewed as being able to produce injectable products at a lower unit price than most hospitals because of a higher throughput of units. Industry would also be able to comply with regulatory requirements for manufacturing, whereas many hospitals are not licensed to produce preprepared injections. Industry also has the potential to facilitate the development of products that offer longer expiration dates than those currently prepared in aseptic suites, as well as products that can be stored at room temperature.

The issue of dose-banding cytotoxics used in clinical trials will require negotiation among trial investigators, pharmacy representatives, and sponsoring pharmaceutical companies. Alternatively, hospitals may set a policy on this for all trials.

Dose-banding entails a simple ad- aptation in current clinical practice, and its adoption by a few large oncology centers in the United Kingdom has created enormous interest in its implementation in other national and international institutions. Our investigation of the concept provides a framework upon which dose-banding can be standardized and expanded.

\section{Conclusion}

Dose-banding is an acceptable practice in the delivery of cytotoxic drugs that can improve services without compromising the quality of care and can improve quality control compared with individualized dose preparation.

\section{References}

1. Reilly JJ, Workman P. Normalisation of anti-cancer drug dosage using body weight and surface area: is it worthwhile? Cancer Chemother Pharmacol. 1993; 32: 411-8.

2. Ratain MJ. Body-surface area as a basis for dosing of anticancer agents: science, myth, or habit. J Clin Oncol. 1998; 16: 2297-8. Editorial.

3. Pharmacist develops dose-banding system. Pharm J. 1996; 256:297. News.

4. Baker JP, Jones SE. Rationalisation of chemotherapy services in the University Hospital Birmingham National Health Science Trust. J Oncol Pharm Pract. 1998; 4:10-4.

5. Desoize B, Robert J. Individual dose adaptation of anticancer drugs. Eur I Cancer. 1994; 30A:844-51.

6. Bailey BJR, Briars GL. Estimating the surface area of the human body. Stat Med. $1996 ; 15: 1325-32$.

7. Plumridge RJ, Sewell GJ. Body surface area dosing of cytotoxic drugs: part 1. Its basis, rationale and predictive accuracy of the formulae. I Oncol Pharm Pract. In press.

8. Priston MJ, Sewell GJ. Stability of three cytotoxic drug infusions in the Graseby 9000 ambulatory infusion pump. J Oncol Pharm Pract. 1998; 4(3):143-9.

9. British pharmacopoeia. London: Her Majesty's Stationery Office; 1998.

10. Needle RJ, Sewell GJ, Summerhayes M. Current issues in centralised intravenous additive services. Hosp Pharm. 1998; 5 :
103-4. 